\title{
Does the ureteric jet Doppler waveform have a role in detecting vesicoureteric reflux?
}

\author{
Kjell Tullus
}

Received: 4 March 2013 /Revised: 11 March 2013 /Accepted: 20 March 2013 /Published online: 1 May 2013

(C) IPNA 2013

\begin{abstract}
Data reported in this issue of Pediatric Nephrology suggest that the ureteric jet Doppler waveform can predict the occurrence of vesicoureteric reflux (VUR). Many different methods are currently used to detect VUR, including traditional X-ray micturating cystourethrogram, indirect and direct nuclear imaging and contrast enhanced ultrasonography. These methods are invasive, do have some radiation burden and are also quite uncomfortable to paediatric patients. This relatively new non-invasive method is therefore of interest, but its efficacy needs to be confirmed in further studies and, in particular, in babies and infants before it can possibly be considered as a good method to provide clinical information on VUR. Once such studies have been performed, this method may also prove to be a useful approach to obtain modern knowledge on the occurrence of VUR in healthy children.
\end{abstract}

Keywords Vesicoureteric reflux · VUR · MCUG ·

Prophylactic antibiotics $\cdot$ Kidney scarring ·

Ultrasonography $\cdot$ Ureteric jet Doppler waveform

\section{Introduction}

The clinical importance of vesicoureteric reflux (VUR) has, during the last decade, become a highly debated issue. Most older guidelines recommend a micturition cystography (MCUG) for children who have had a urinary tract infection (UTI). More recent guidelines, written by the National Institute of Health and Clinical Excellence (NICE) in the UK and the American Academy of Pediatrics, recommend a

\section{K. Tullus $(\bowtie)$}

Paediatric Nephrology,

Great Ormond St Hospital, Great Ormond Street,

London WC1N 3JH, UK

e-mail: Kjell.Tullus@gosh.nhs.uk more selective and much more restrictive approach on when to do an MCUG $[1,2]$.

\section{Reasons for changes}

This change in recommended practices has several underlying reasons. Questions have been raised on the actual benefit in terms of clinical management of knowing about VUR in a child who has experienced a single uncomplicated episode of acute pyelonephritis [3]. The efficacy of anti-reflux surgery has been compared to that of prophylactic antibiotics in several well-performed studies [4-7]. In these studies, surgery could not be shown to reduce the number of children who developed new renal scars; this was true also for children with quite marked reflux, namely, Grade III or IV.

The efficacy of prophylactic antibiotics in preventing UTIs and further renal scarring has been tested in a number of recent studies [8-12] which were summarised in a metaanalysis in American guidelines [1]. This meta-analyse could not show any benefit from antibiotic prophylaxis over placebo treatment - irrespective of grade of VUR.

Another important reason to radically reduce the use of MCUG is that most children find the procedure quite challenging and painful. The procedure is also associated with a small radiation burden and the risk of introducing an infection.

\section{Natural prevalence of VUR}

The prevalence of VUR in healthy children is not fully known. It has, based on results from early studies, been assumed to be very low (only a few percent). In contrast, one early study did show that $30 \%$ of 102 healthy children between the age of 2 days and 5 years had VUR [13] and 
that as many as $64.7 \%$ of infants showed reflux. The reflux seemed to disappear with age, and none of the older children who were studied at the age 5 years showed VUR. This study has, however, been criticised for using a too high filling pressure of the bladder during the MCUG and thus of "creating" VUR.

A recent retrospective Finnish study re-evaluated the diagnosis of UTI in 406 children aged less than 5 years who had had an MCUG [14]. The children were categorised into three groups on the basis of their initial urine findings [14]: those having had a certain $(n=276)$, possible $(n=46)$ or improbable $(n=25)$ UTI. The occurrence of VUR was very similar in the three groups, namely, 36, 28 and $36 \%$, respectively.

In another study conducted by the same group, the UTI diagnosis in 2,036 children who had had an MCUG was reclassified. The children were grouped into five groups according to their initial urine data: proven, likely, unlikely or false UTI and no microbial data. The occurrence of VUR was $37.4 \%$ in those with proven UTI and $34.8 \%$ in those with a false diagnosis [15]. These data bring the previously found strong relationship between VUR and febrile UTI into question.

Interestingly, similar occurrences of VUR have been found when siblings were screened for VUR due to one sibling previously being diagnosed with reflux. A metaanalysis showed a prevalence of $27.4(2.9-51.9) / 100$ screened siblings [16].

\section{Gender difference}

Modern guidelines and most clinicians still acknowledge that there are clinical circumstances where knowledge of the reflux status of a certain child is clinically important and will influence further management. The meta-analysis in the American guidelines did not separately analyse boys and girls [1]. The largest study on prophylactic antibiotics in children with high-grade reflux, the Swedish reflux study, did however find a significant gender difference $[1,8]$. Treatment with prophylactic antibiotics in girls, but not in boys, reduced both the number of infections and the number of new renal scars [17]. The lack of benefit in the boys was due to the low number of recurrent infections that occurred in those boys who were not treated with antibiotics. The use of antibiotics in boys thus had very small chance to improve the outcome.

\section{Other imaging modalities}

Several other imaging modalities have been developed to investigate the occurrence of VUR, such as direct and indirect nuclear studies and ultrasound imaging with ultrasound contrast medium injected into the bladder [18]. Both direct nuclear imaging and ultrasound with contrast medium involves catherisation of the bladder. Indirect nuclear imaging can only be performed in potty trained children and is thus not possible in the most important group, namely, infants and toddlers. All of these methods also show a lower sensitivity than a regular MCUG [19].

It is therefore of great interest to develop accurate noninvasive methods to detect VUR. Consequently, the study by D'Souza et al. on the ureteric jet Doppler wave form as a marker for VUR in this issue of Pediatric Nephrology is an interesting step forward [20].

Researchers from Hong Kong have previously analysed the ureteric Doppler wave form in 1,010 subjects of all ages [21]. They found six different patterns, one of which was monophasic and seemed to represent an immature form. In a later study, the same group investigated 241 healthy and 98 other children who had a UTI [22]. The monophasic pattern was found in $29 \%$ of the healthy children and varied greatly with age; in comparison, it was present in most infants before the age of 6 month and in $90.5 \%$ of the children with proven VUR.

A research group in Slovenia has also investigated whether wave form analysis is a reliable predictor of VUR. In one study [23], they compared the waveform method with echoenhanced voiding ultrasonography in 75 children between the age of 3 and 12 years. They found that the Doppler method had $88.5 \%$ sensitivity and $82.3 \%$ specificity compared to the voiding ultrasonography. In another study, the same group showed a good correlation between voiding ultrasonography and conventional X-ray MCUG [24].

In the study reported in the present issue of Pediatric Nephrology researchers from Bangalore in India take these findings further and compare analyses of the wave form pattern with the present gold standard, MCUG [20]. They unfortunately excluded the most interesting group of children, those younger than 2 years of age. These authors found the sensitivity for the wave form analyses to be $80.3 \%$ and specificity $87.9 \%$ in children aged $2-18$ years.

In summary, analysis of the ureteric Doppler wave form may provide a future tool to investigate children for VUR. However, further studies are needed that compare this method with the present gold standard, X-ray MCUG. Such studies must also be performed in children in the youngest age group. A high proportion of infants show an immature Doppler pattern, and for this reason they were excluded from the recent study of D'Souza et al. [20]. An alternative interpretation of the findings could be that a large group of young children actually have VUR. This possibility is supported by the studies described above from the Finnish group.

If the wave form analysis approach is properly evaluated it might provide a tool that could provide a great deal of 
information on the physiology and pathology of VUR. This method may also provide the possibility to learn more about the natural occurrence of VUR.

\section{References}

1. Roberts KB, Downs SM, Finnell SM, Hellerstein S, Shortliffe LD, Wald ER, Zerin JM, Davidson C, Subcommittee on Urinary Tract Infection (2011) Urinary tract infection: clinical practice guideline for the diagnosis and management of the initial UTI in febrile infants and children 2 to 24 months. Pediatrics 128:595-610

2. Mori R, Lakhanpaul M, Verrier-Jones K (2007) Diagnosis and management of urinary tract infection in children: summary of NICE guidance. Br Med J 335:395-397

3. Marks SD, Gordon I, Tullus K (2008) Imaging in childhood urinary tract infections: time to reduce investigations. Pediatr Nephrol 23:9-17

4. (1987) Prospective trial of operative versus non-operative treatment of severe vesicoureteric reflux in children: 5 years' observation. Birmingham Reflux Study Group. Br Med J (Clin Res Ed) 295:237-241

5. Olbing H, Smellie JM, Jodal U, Lax H (2003) New renal scars in children with severe VUR: a 10-year study of randomized treatment. Pediatr Nephrol 18:1128-1131

6. Smellie JM, Tamminen-Mobius T, Olbing H, Claesson I, Wikstad I, Jodal U, Seppanen U (1992) Five-year study of medical or surgical treatment in children with severe reflux: radiological renal findings. The International Reflux Study in Children. Pediatr Nephrol 6:223-230

7. Smellie JM, Barratt TM, Chantler C, Gordon I, Prescod NP, Ransley PG, Woolf AS (2001) Medical versus surgical treatment in children with severe bilateral vesicoureteric reflux and bilateral nephropathy: a randomised trial. Lancet 357:1329-1333

8. Brandstrom P, Esbjorner E, Herthelius M, Swerkersson S, Jodal U, Hansson S (2010) The swedish reflux trial in children: III. Urinary tract infection pattern. J Urol 184:286-291

9. Craig JC, Simpson JM, Williams GJ, Lowe A, Reynolds GJ, McTaggart SJ, Hodson EM, Carapetis JR, Cranswick NE, Smith G, Irwig LM, Caldwell PH, Hamilton S, Roy LP (2009) Antibiotic prophylaxis and recurrent urinary tract infection in children. $\mathrm{N}$ Engl J Med 361:1748-1759

10. Montini G, Rigon L, Zucchetta P, Fregonese F, Toffolo A, Gobber D, Cecchin D, Pavanello L, Molinari PP, Maschio F, Zanchetta S, Cassar W, Casadio L, Crivellaro C, Fortunati P, Corsini A, Calderan A, Comacchio S, Tommasi L, Hewitt IK, Da DL, Zacchello G, Dall'Amico R (2008) Prophylaxis after first febrile urinary tract infection in children? A multicenter, randomized, controlled, noninferiority trial. Pediatrics 122:1064-1071
11. Pennesi M, Travan L, Peratoner L, Bordugo A, Cattaneo A, Ronfani L, Minisini S, Ventura A (2008) Is antibiotic prophylaxis in children with vesicoureteral reflux effective in preventing pyelonephritis and renal scars? a randomized, controlled trial. Pediatrics 121:e1489-e1494

12. Roussey-Kesler G, Gadjos V, Idres N, Horen B, Ichay L, Leclair MD, Raymond F, Grellier A, Hazart I, de Parscau PL, Salomon R, Champion G, Leroy V, Guigonis V, Siret D, Palcoux JB, Taque S, Lemoigne A, Nguyen JM, Guyot C (2008) Antibiotic prophylaxis for the prevention of recurrent urinary tract infection in children with low grade vesicoureteral reflux: results from a prospective randomized study. J Urol 179:674-679

13. Kollermann MW, Ludwig H (1967) On vesico-ureteral reflux in normal infants and children. Z Kinderheilkd 100:185-191

14. Venhola M, Hannula A, Huttunen NP, Renko M, Pokka T, Uhari M (2010) Occurrence of vesicoureteral reflux in children. Acta Paediatr 99:1875-1878

15. Hannula A, Venhola M, Renko M, Pokka T, Huttunen NP, Uhari M (2010) Vesicoureteral reflux in children with suspected and proven urinary tract infection. Pediatr Nephrol 25:1463-1469

16. Skoog SJ, Peters CA, Arant BS Jr, Copp HL, Elder JS, Hudson RG, Khoury AE, Lorenzo AJ, Pohl HG, Shapiro E, Snodgrass WT, Diaz M (2010) Pediatric Vesicoureteral Reflux Guidelines Panel Summary Report: Clinical practice guidelines for screening siblings of children with vesicoureteral reflux and neonates/infants with prenatal hydronephrosis. J Urol 184:1145-1151

17. Brandstrom P, Neveus T, Sixt R, Stokland E, Jodal U, Hansson S (2010) The Swedish reflux trial in children: IV. Renal damage. J Urol 184:292-297

18. Kenda RB, Novljan G, Kenig A, Hojker S, Fettich JJ (2000) Echoenhanced ultrasound voiding cystography in children: a new approach. Pediatr Nephrol 14:297-300

19. Gordon I, Peters AM, Morony S (1990) Indirect radionuclide cystography: a sensitive technique for the detection of vesicoureteral reflux. Pediatr Nephrol 4:604-606

20. D'Souza MK, Verma NS, Das K, Phadke KD, Iyengar A (2013) Detecting reflux:does ureteric jet Doppler waveform have a role? Pediatr Nephrol. doi:10.1007/s00467-013-2460-5

21. Leung VY, Metreweli C, Yeung CK (2002) The ureteric jet Doppler waveform as an indicator of vesicoureteric sphincter function in adults and children. An observational study. Ultrasound Med Biol 28:865-872

22. Leung VY, Metreweli C, Yeung CK (2002) Immature ureteric jet Doppler patterns and urinary tract infection and vesicoureteric reflux in children. Ultrasound Med Biol 28:873-878

23. Kljucevsek D, Kljucevsek T, Kersnik LT, Kenda RB (2009) Ureteric jet Doppler waveform: is it a reliable predictor of vesicoureteric reflux in children? Pediatr Nephrol 24:313-318

24. Kljucevsek D, Battelino N, Tomazic M, Kersnik LT (2012) A comparison of echo-enhanced voiding urosonography with X-ray voiding cystourethrography in the first year of life. Acta Paediatr 101:e235-e239 